\title{
CONSERVACIÓN AMBIENTAL Y APROVECHAMIENTO AGROPECUARIO: EL CASO DEL PARQUE NATURAL AGRARIO «LOS CARRIZALES» (ELCHE, ALICANTE) ${ }^{1}$
}

\author{
José Antonio Segrelles Serrano \\ Departamento de Geografía Humana. Universidad de Alicante \\ ja.segrelles@ua.es
}

Hemos hurgado en el corazón de los montes, hemos bajado al fondo de los barrancos nunca hollados por el hombre, hemos vulnerado las rocas, atentado contra un equilibrio ancestral, y lo estamos pagando. La naturaleza se ha rebelado contra nosotros y se ha defendido, devolviéndonos ofensa por ofensa... (Luciano G. Egido, en Los túneles del paraíso, Barcelona, Tusquets, 2009, p. 220).

\section{RESUMEN}

Las limitaciones del modo de producción capitalista convierten el desarrollo sostenible en una quimera. No puede existir sostenibilidad en el seno de un sistema caracterizado por la depredación de los recursos humanos y naturales. Pese al auge del conservacionismo y de la ecología profunda, existen varios casos en los que la viabilidad económica del sector agropecuario no sólo no está reñida con la integridad ambiental y la preservación de los

Fecha de recepción: octubre 2011.

Fecha de aceptación: enero 2013.

1 Este artículo se enmarca en el proyecto de investigación Análisis territorial del capital social en espacios naturales protegidos: Indicadores de desarrollo socioeconómico, financiado por el Ministerio de Ciencia e Innovación, dentro de su Programa de Ayudas para la Realización de Acciones Especiales de I+D+i (Ref.: CS02008-02919/ GEOG), y dirigido por la Dra. Concepción Foronda Robles (Departamento de Geografía Humana. Universidad de Sevilla). Agradezco la amabilidad y las desinteresadas aportaciones de D. Juan Miguel Montaner, así como la atenta ayuda de Dña. María Antón, vicepresidente y administrativa, respectivamente, de la Comunidad de Regantes de Carrizales. 
ecosistemas, sino que el aprovechamiento económico y la protección ecológica forman un binomio equilibrado, armonioso y mutuamente dependiente.

Palabras clave: Conservación ambiental, aprovechamiento agropecuario, Parque Natural Agrario «Los Carrizales», Elche, Alicante, España.

\section{ABSTRACT}

The limitations of capitalistic production methods turn sustainable development into a pipe dream. No sustainability is possible within a system characterised by the depredation of human and natural resources. Despite the rise of a conservationist and deeply ecological ideology, there are several cases where the economic viability of agriculture and stockbreeding is not at odds with environmental integrity and the protection of ecosystems; here, agricultural and livestock exploitation and ecological protection actually make a balanced, harmonious and mutually dependent couple.

Key words: Environmental conservation, agricultural exploitation, Los Carrizales Agricultural Natural Park., Elche, Alicante, Spain.

\section{INTRODUCCIÓN}

Desde la redacción del denominado Informe Brundtland (1987) y su difusión en la Cumbre de la Tierra de Río de Janeiro (1992) se repite y casi todo el mundo tiene asumido que la ecología es un valor fundamental para la vida humana y que el desarrollo sostenible consiste en poner en marcha tres tipos de solidaridad de manera simultánea: dentro de la propia comunidad, con los demás habitantes del planeta y con las generaciones futuras. Este barniz solidario motiva que los conceptos de ecología y desarrollo sostenible resulten atractivos para los medios de comunicación y para el conjunto de la sociedad, pues albergan ideas aceptables para todos los agentes socioeconómicos, políticos, culturales, religiosos y ambientales. Dichas nociones se han magnificado de forma interesada al mismo tiempo que se integran en la engrasada maquinaria de la mercadotecnia y la publicidad. Por lo tanto, se ha convertido en algo de buen tono y propio de ciudadanos comprometidos, sensibles y progresistas hablar de ecología, desarrollo sostenible, desarrollo rural integral, desarrollo rural endógeno o recursos ambientales en cuanto aparece la mínima oportunidad, sin pensar que estos conceptos encierran en sí mismos una contradicción insuperable con la esencia inherente del modo de producción capitalista, pues éste genera antagonismos que lo hacen insostenible.

No puede ser sostenible ni solidario un sistema cuya naturaleza se basa en la apropiación privada de la riqueza conseguida con el trabajo de todos, la maximización de las ganancias con la mínima inversión, la acumulación de beneficios en el menor tiempo posible, el afán de convertirlo todo en mercancía, la instauración de la competencia de todos contra todos y la sacralización del mercado como principal mecanismo que articula los procesos de producción, distribución y consumo. El modo de producción capitalista tiene limitaciones insalvables porque no puede renunciar a la explotación de la mano de obra ni a la utilización abusiva 
de los recursos naturales si quiere seguir reconociéndose como tal. Esta realidad pone en peligro constante la viabilidad de los ecosistemas y genera un crecimiento que es cualquier cosa menos sostenible. La necesidad de acumulación y de que los beneficios sean elevados de manera rápida y constante le «obligan» a recurrir de forma sistemática a la conquista de nuevas fuentes de producción y consumo, lo que deviene en una utilización masiva e irracional de los recursos naturales y en un deterioro del ambiente que en muchas ocasiones se manifiesta irrecuperable.

Al mismo tiempo, desde hace algunas décadas también se abre paso con más fuerza cada vez ese esquema ideológico que se ha convenido en denominar conservacionismo o ecología profund $a^{2}$, es decir, un tipo de ecología que no considera la existencia humana y aspira a conservar el medio pero sin la presencia de las personas. Los defensores de este movimiento consideran que las comunidades humanas y la vida silvestre son sencillamente incompatibles, pues tanto los individuos como las actividades que éstos desarrollan resultan destructores de la naturaleza por propia definición (Sessions, 1981; Devall y Sessions, 1985). En el caso de muchos países subdesarrollados, la aplicación de esta ideología conservacionista implica el categórico desplazamiento de los pueblos instalados en territorios bien dotados de recursos naturales, de forma que los campesinos y los indígenas ceden el paso a los ricos y terratenientes que pueden dedicarse a la ecología y a la preservación de una naturaleza prístina que se reserva a aquellos que pueden pagarla y, por lo tanto, disfrutarla (Dilitio, 2006; Dowie, 2007). Por el contrario, en el mundo desarrollado, como es el caso de Europa, donde predominan los paisajes culturales frente a los naturales, el conservacionismo y la ecología profunda no se pueden ejercitar de una manera tan rotunda por medio del desarraigo de las comunidades que allí habitan, pero sí se intenta evitar, o por lo menos limitar, las actividades económicas en las zonas que se desea proteger. Estas limitaciones, que tienen sentido en el caso de la industria o la minería, también se extienden muchas veces a los aprovechamientos agropecuarios y forestales, lo que en algunas áreas ha dado lugar a la protesta de los agricultores y ganaderos asentados en el paraje natural en cuestión.

En cualquier caso, y como objetivo principal de esta investigación, se puede decir que tanto la sostenibilidad como el conservacionismo constituyen dos caras de la misma moneda, pues ambos modelos o paradigmas se encuentran condicionados por los imperativos del modo de producción capitalista, exigencias que entran en franca relación dialéctica con las actividades agrarias y con la vida socioeconómica y cultural de las comunidades rurales que habitan y producen dentro o en las proximidades de los espacios naturales que se desea proteger y conservar. Pese a todo, es cierto que el sistema capitalista ofrece grietas o fisuras que pueden ser aprovechadas para alterar este estado de cosas. Existen algunos ejemplos en los que la viabilidad económica de la agricultura y la ganadería no está reñida con la integridad ambiental, la preservación de los ecosistemas y la conservación de la biodiversidad, apostando sin reservas por la diversificación económica de las áreas rurales y el aprovechamiento de todas y cada una de las posibilidades que ofrece el entorno para generar rentas complementarias. La práctica de la actividad agraria y la preservación de los espacios naturales forman en numerosas ocasiones un binomio generador de debates y conflictos, tal como se

2 El término movimiento de ecología profunda fue introducido en la literatura ecológica en 1973 por el filósofo y montañista noruego Arne Næss. 
demostró en la Jornada de Reflexió sobre l'Activitat Agrària i la Seva Implicació en la Preservació del Espais Naturals, organizada por la Fundació Agroterritori y la Universitat de Girona y celebrada en Girona en octubre de $2011^{3}$.

Un caso destacable de equilibrio simbiótico entre las actividades agropecuarias y la preservación del ambiente y la biodiversidad se encuentra en el denominado Parque Natural Agrario «Los Carrizales», impulsado por la Comunidad de Regantes de Carrizales ${ }^{4}$ y localizado en el municipio alicantino de Elche a caballo entre dos espacios naturales protegidos: El Hondo y Las Salinas de Santa Pola. Dicho parque natural, donde se desarrolla la actividad agropecuaria, representa un modelo de armonía en el que la agricultura no sólo no destruye el paisaje ni el territorio, sino que se erige como una manifestación económica necesaria para mantener el ecosistema y la biodiversidad del área en la que se ubica, aspectos que constituyen la hipótesis de partida de esta reflexión. A este respecto hay que tener en cuenta que el paisaje agrícola no es un fin en sí mismo, sino la consecuencia del dinamismo de una actividad agrícola productiva que genera paisajes culturales de gran valor, resultado en su inmensa mayoría del uso agropecuario del espacio. Esta dimensión cultural constituye una característica clave de su identidad y de sus funciones socioeconómicas, como sucede en la mayor parte del continente europeo.

Asimismo, iniciativas similares también se encuentran en los casos del Parc Agrari del Baix Llobregat ${ }^{5}$ (Montasell, 2008; Terricabras, 2005; Verdaguer, 2010), el Parc Agrari de Sabadell ${ }^{6}$ (Freire (2011), el Parque Agrícola del Valle del Guadalhorce ${ }^{7}$, el Parco di Portofino $^{8}$, cerca de Génova, el Parco Agrícolo Sud Milano ${ }^{9}$, en Milán, o el Groupe d'Action Locale (GAL) Leader Seine Aval ${ }^{10}$, en el área metropolitana de París.

El artículo se estructura en dos grandes apartados. En el primero de ellos se estudian de forma breve las principales características, exigencias y limitaciones del conservacionismo y la ecología profunda con el ánimo de encuadrar teóricamente la cuestión tratada, mientras que en el segundo se plasman la experiencia, motivaciones, estrategias y saber hacer de los agricultores, ganaderos y propietarios de humedales asociados a la Comunidad de Regantes de Carrizales que en 2008 pusieron en marcha el proyecto de Parque Natural Agrario «Los Carrizales» como ejemplo simbiótico de aprovechamiento agropecuario y conservación ambiental.

\section{NATURALEZA SIN SERES HUMANOS}

Lo primero que se debe tener en cuenta es que las políticas de conservación y gestión ambientales nunca han sido tan determinantes como en la actualidad para el desenvolvimiento de muchos países subdesarrollados. Sus gobiernos en todos los niveles administrati-

3 http://www.agroterritori.org/ficha.php?idioma=ca\&id_nivell2=16\#doc524

4 http://www.carrizales.es

5 http://www.diba.cat/parcsn/parcs/index.asp?Parc=9

6 Véase el trabajo de Sonia Freire Trigo (2011).

7 http://www.parqueagricolaguadalhorce.com/index.php/parque-agricola-en-el-valle-del-guadalhorce

8 http://www.parcoportofino.it/page.aspx?codice $=0000000083$

9 http://www.provincia.milano.it/parcosud

$10 \mathrm{http}: / /$ leaderseineaval.com/joomla1.5/index.php?option=com_content $\&$ view=article \&id=24\&Itemid=20 
vos (local, regional y nacional) son cómplices o víctimas de los proyectos ecológicos que se ejecutan en sus jurisdicciones. El negocio de los servicios ambientales genera miles de millones de dólares de ganancias en todo el mundo, lo que significa que existe una multiplicidad inusitada de intereses económicos y geopolíticos que proliferan ligados a él. Por supuesto, los grandes beneficiarios son las firmas transnacionales más dinámicas y poderosas, la gran banca internacional y los países centrales de los que proceden esas compañías de actuación global.

La mayoría de los conflictos bélicos que se han desarrollado durante las últimas décadas del siglo XX han tenido como origen la lucha por el control de los recursos naturales, sobre todo los hidrocarburos. Con toda seguridad éste también será el motivo de las guerras que se produzcan en la presente centuria, aunque ahora se sumará sin duda la escasez de agua y las disputas por la dominación de los recursos hídricos. No obstante, uno de los principales problemas para el capitalismo avanzado y mundializado son los propios seres humanos, ya que al parecer sobran habitantes en el planeta y hacia esta cuestión se encaminan sus estrategias (Dilitio, 2006). A este respecto merece la pena recordar el libro titulado Informe Lugano, de S. George (2001), donde se fantasea sobre el encargo de un informe secreto a un equipo multidisciplinario de científicos con el objeto de que aporten las estrategias que se deben seguir para que el capitalismo consiga sobrevivir a los futuros retos económicos, sociales y ambientales. Precisamente, una de las recomendaciones, dado que según dicha autora el capitalismo no puede tener éxito con una población mundial de más de 6.500 millones de habitantes (casi 7.000 millones en el momento actual), es eliminar a miles de millones de personas «superfluas».

Es de sobra conocido que a partir de la conquista y expolio de América por parte de españoles y portugueses, con especial énfasis durante la etapa colonial iniciada por los europeos en el siglo XIX, legiones de indígenas de todo el mundo han sido desarraigadas de sus tierras ancestrales para que la obtención de petróleo y minerales, la extracción de maderas y las plantaciones, primero, y las grandes haciendas y negocios agroindustriales, después, pudieran explotar los recursos naturales sin obstáculos y con total impunidad. La participación activa de muchas firmas transnacionales en la destrucción natural y cultural de los países subdesarrollados es palmaria. Sin embargo, pocas personas perciben que algo similar está ocurriendo en la actualidad por una causa más noble y socialmente aceptada: la conservación de las tierras, la naturaleza y la vida salvaje (Dowie, 2007). Mucho menos se conoce que muchas de estas adquisiciones de tierras que tienen como objetivo primordial el ejercicio de una ecología profunda las han realizado varias organizaciones o fundaciones relacionadas de algún modo con la protección de la naturaleza, como sucede con la Fundación ECOS, World Wildlife (WWF), Conservation International (CI), Wildlife Conservation Society (WCS), The Nature Conservancy (TNC), Unión Mundial para la Conservación de la Naturaleza (UICN) o la propia UNESCO, sin reparar apenas en las nefastas consecuencias que sus estrategias tienen sobre las culturas locales y sobre la agricultura y el modo de vida tradicional de los indígenas y campesinos de los países donde actúan.

Estas organizaciones dedicadas a la conservación ambiental suelen trabajar en numerosas ocasiones con varias compañías transnacionales cuyo papel en la extracción abusiva de materias primas y, por ende, en el deterioro de los ecosistemas, queda fuera de toda duda, pues no faltan episodios de agresión al medio en la actuación de empresas como Shell, Bri- 
tish Petroleum, Coca Cola, Nestlé, Bechtel, Veolia, Boise Cascade, ENDESA, Repsol, ENCE o Botnia. En este tipo de asociaciones también suelen participar diversas organizaciones que se encuentran financiadas por las fundaciones creadas por los grandes magnates estadounidenses: Morgan, Soros, Rockefeller, Ford o Turner. Un papel conservacionista muy activo ha sido desempeñado hasta el momento actual en Argentina y Chile por el multimillonario Douglas Tompkins por medio de la empresa The Patagonia Land Trust (Dilitio, 2006), ya que este ecologista profundo ha adquirido enormes extensiones de tierra en estos países como parte de su proyecto personal de conservación de la naturaleza. Esto ha suscitado acres polémicas en las sociedades argentina y chilena porque el nuevo propietario no sólo desplaza a los habitantes autóctonos cuando viven sobre recursos ricos en biodiversidad, sino porque además se dice que la organización que lidera (Conservation Land Trust) es el «caballo de Troya» del Banco Mundial (BM) con el objeto de controlar los abundantes recursos hídricos, minerales, agropecuarios y naturales de la zona. Lo peor de todo es que sus compras se hicieron bajo legislación estadounidense y fueron patrocinadas por la UNESCO por su finalidad y carácter ecológico.

Estas circunstancias constituyen una evidencia más del todavía vigente problema que representa la propiedad de la tierra en muchos lugares del globo: concentración de la propiedad, latifundismo, adquisición de tierras de cultivo por parte de países extranjeros, tierras ociosas, violencia contra los campesinos y su criminalización y desarraigo, entre otras. Es improbable, por lo tanto, que dichas iniciativas encuentren demasiada oposición porque la ecología es considerada como una causa noble por la mayor parte de la sociedad, aunque luego se produzcan auténticas catástrofes ambientales y sociales y muchos países pierdan la soberanía territorial y alimentaria y el control de sus recursos naturales.

El basamento ideológico del conservacionismo está complementado y apoyado por el surgimiento de organizaciones que pretenden preservar la naturaleza planteando una ecología profunda, es decir, un tipo de ecología que, como ha quedado dicho en la introducción, no considera la existencia humana y aspira a conservar el medio pero sin la presencia de personas. Este movimiento lo que hace en realidad es impulsar el desarraigo de las comunidades que habitan en aquellos territorios donde abundan los recursos naturales, de modo que al final los desplazados son los campesinos e indígenas del lugar elegido con el objeto de preservar ciertos santuarios naturales para el uso y disfrute de quienes puedan pagarlo. Este modelo de áreas protegidas, creado en Estados Unidos a mediados del siglo XIX, es una de las políticas conservacionistas más utilizada en los países subdesarrollados. Los conservacionistas norteamericanos, partiendo del contexto de la rápida expansión urbana e industrial del país, proponían la creación de «islas» de conservación biológica, de gran belleza escénica, donde el habitante urbano pudiese apreciar y reverenciar la naturaleza salvaje y disponer de lugares en los que poder satisfacer su necesidad de recreación y renovación espiritual. De ahí que A. C. Diegues (2005) hable del «mito moderno de la naturaleza intocada».

La ideología que subyace en este modelo se basa en la visión de los seres humanos como entes necesariamente destructores de la naturaleza. Así se puede comprobar en los ocho principios de la plataforma que impulsa el movimiento de la ecología profunda, recogidos por B. Dewall y G. Sessions (1985). Estos principios, que A. Arness y el propio G. Sessions crearon en 1984, son los siguientes: 
1. El bienestar y florecimiento de la Vida humana y no humana en la Tierra tiene valor en sí misma. Este valor es independiente de la utilidad que tenga el mundo no humano para los propósitos de los humanos.

2. La riqueza y diversidad de las formas humanas contribuyen a la realización de estos valores, siendo también valores en sí mismos.

3. Los humanos no tienen derecho a reducir la riqueza y diversidad, excepto en casos de satisfacer necesidades humanas vitales.

4. El florecimiento de la vida humana y de las culturas es compatible con una disminución sustancial de la población humana. El florecimiento de la vida no humana requiere tal disminución.

5. La interferencia humana actual con el mundo no humano es excesiva, y esa situación está empeorando rápidamente.

6. Por lo tanto, las políticas tienen que cambiar. Estas políticas afectan a la economía básica y a las estructuras tecnológicas e ideológicas. El resultado será profundamente diferente de lo que sucede en el presente.

7. El cambio ideológico se refiere más bien a una apreciación de la calidad de vida (relacionado con situaciones de valores inherentes) más que con la adhesión a un estándar de vida cada vez más superior. Existirá una gran conciencia sobre la diferencia entre grande y gran.

8. Quienes subscriben los puntos precedentes tienen la obligación de tratar de implementar, directa o indirectamente, los cambios necesarios.

Como puede comprobarse, se aboga de forma clara y sin eufemismos por la conservación de la naturaleza y la biodiversidad, pero sin la presencia humana porque para estos ecólogos profundos y conservacionistas la vida silvestre y las comunidades humanas son incompatibles. Cuando los conservacionistas internacionales tienen suficiente poder y capacidad de persuasión sobre algunos de los gobiernos que rigen los destinos de los países empobrecidos, pueden producirse catástrofes culturales y humanas como la que sufrió el pueblo batwa en Uganda durante el decenio de los años noventa del siglo pasado, que fue expulsado de sus tierras ancestrales cuando éstas fueron designadas formalmente como parques nacionales (Dowie, 2007).

Si se tiene en cuenta que las primeras interesadas en mantener un ambiente óptimo, pues en él encuentran su medio de vida y supervivencia, son las propias comunidades locales, es ilógico e hipócrita acusarlas de degradar los ecosistemas y perjudicar a la biodiversidad con sus actividades (agricultura, ganadería, caza, pesca, recolección) con el fin de que dicha acusación sirva de excusa para desalojarlas de su hábitat en contra de su voluntad y que formen parte de esa nueva masa humana que se podría denominar «refugiados ambientales», ya que muchas veces se les recluye en campamentos precarios y siempre se les impide regresar a esos territorios en los que durante generaciones desarrollaron sus vidas y que ahora los conservacionistas quieren preservar, aunque aislando la vida salvaje y dejándola sin pobladores.

Todo esto significa que cuando se han transplantado los modelos estadounidenses a las realidades de los países subdesarrollados han surgido conflictos de difícil solución. Se debe tener en cuenta que los bosques y selvas de estos países han estado habitados por poblaciones indígenas y otros grupos tradicionales que desarrollaron formas de apropiación comunal 
de los espacios y recursos naturales. Por medio de un gran conocimiento de la naturaleza, esas comunidades pudieron crear ingeniosos sistemas para integrar la fauna y la flora y al mismo tiempo proteger, conservar e incluso potenciar la diversidad biológica. Muchas áreas naturales que se desea preservar son ricas en biodiversidad precisamente porque sus moradores ancestrales comprendieron el valor y los mecanismos de la diversidad biológica. La expulsión de los indígenas de sus territorios no sólo es una injusticia social y una iniquidad moral, sino también una tropelía ecológica muy alejada de la pretendida y demandada sostenibilidad.

Con el establecimiento de los parques naturales se imponen los mitos recientes (como el de la naturaleza salvaje, prístina, intocada) sobre los mitos ancestrales (el ser humano como ente que forma parte de la naturaleza), lo que agudiza los conflictos por el control del espacio y la preservación de ciertos modos de vida (Diegues, 2005). En este contexto, resulta difícil comprender que la vida humana y sus actividades sobren en los espacios naturales preservados y se expulse a los habitantes tradicionales y, sin embargo, se permitan ciertas facilidades turísticas y se construyan hoteles y albergues para alojar a los usuarios de las reservas naturales.

Salvando las distancias, en los países desarrollados también están proliferando ideologías cuyo fundamento es similar al que presta apoyo al conservacionismo y a la ecología profunda, puesto que, como indica J. Montasell (2008), a los problemas tradicionales de la agricultura y los espacios agrarios periurbanos ahora se suma otra dificultad añadida consistente en acreditar la defensa de las áreas libres en los alrededores de las ciudades, pero sin la presencia de la actividad agropecuaria en ellas. Se trata en resumidas cuentas de reducir el territorio agrorrural a una especie de parque temático en el que todo resulta artificial, impersonal y descontextualizado y donde la conservación se justifica bajo criterios que se basan en la preservación de la biodiversidad y los recursos naturales o en una concepción paisajística que en realidad pretende excluir la actividad agraria o concederle un valor meramente costumbrista y pintoresco. En el caso europeo, estas iniciativas están más ligadas de lo que parece a simple vista con el cambio de paradigma o modelo que condujo a la Política Agrícola Común (PAC) a reformarse con una visión integrada, multifuncional y global del mundo rural desde sus iniciales planteamientos de productividad agraria a ultranza, pues numerosos proyectos de desarrollo rural marginan a la agricultura, otorgan todo su apoyo al turismo y actúan para que las nuevas fuentes de ingresos que el campo necesita sustituyan, y no complementen, a las rentas agropecuarias (Segrelles, 2007).

\section{NATURALEZA Y AGRICULTURA: EL PARQUE NATURAL AGRARIO «LOS CARRIZALES»}

El Parque Natural Agrario «Los Carrizales» constituye un ejemplo muy logrado de simbiosis, equilibrio y armonía entre las actividades agropecuarias, la conservación de la biodiversidad vegetal y animal y la integridad del ecosistema. Los agricultores y ganaderos que aquí desarrollan su actividad tienen bien asumido que es posible aprovechar las grietas del sistema capitalista para generar rentas utilizando todas las oportunidades que ofrece el entorno, pero sin agredir al medio y manteniendo la agricultura como núcleo fundamental de sus estrategias. 
Este parque agrario y natural se localiza en el área periurbana de la ciudad de Elche, tercera urbe de la Comunidad Valenciana desde el punto de vista demográfico con 230.354 habitantes en $2011^{11}$, aunque su función no es la de ser una simple zona natural, ni tampoco un parque temático y etnográfico, un museo viviente o una reserva de la riqueza y variedad biológica del área, ni siquiera, en palabras de J. Montasell (2008) para el caso del Parc Agrari del Baix Llobregat, un método de momificación del espacio agrario, sino que constituye una herramienta de gestión eficiente de las actividades agropecuarias. Dicha gestión también implica una ejercicio de voluntad para intervenir en la conservación del territorio, en la garantía de que continúe la utilización agraria del suelo y en el fomento de programas concretos de desarrollo agrícola y rural. Además, este parque agrario constituye un agroecosistema con entidad propia que está enclavado en un conjunto territorial holístico, pues no se pueden comprender las características globales de este sistema analizando por separado las partes o elementos que lo componen. Tampoco se debe olvidar su incalculable valor cultural ligado a su mismo origen como espacio de cultivo y a la singular organización del regadío en esta área y otras próximas (Canales y Segrelles, 2010). Aquí se cumple a la perfección esa idea que sostiene que las variaciones biofísicas en los territorios y, sobre todo, la secular utilización de los mismos por parte de los seres humanos tienen como resultado la existencia de una gran diversidad paisajística y la existencia de paisajes culturales muy valiosos, resultado en su inmensa mayoría del uso agropecuario del espacio. Este aspecto cultural del Parque Natural Agrario «Los Carrizales» representa un rasgo clave de su identidad y de sus actuales funciones socioeconómicas y ambientales.

\section{Localización y antecedentes histórico-físicos del Parque Natural Agrario «Los Carrizales»}

Este parque natural agrario es una iniciativa desarrollada por 400 agricultores organizados en torno a la Comunidad de Regantes de Carrizales, entidad de derecho público sin ánimo de lucro adscrita a la Confederación Hidrográfica del Segura. Tiene su origen histórico en la Real Cédula de 1748 concedida por el rey Fernando VI al duque de Arcos, señor de estas tierras, comprendiendo el área denominada de Bassa Llarguera, almarjal desecada al mismo tiempo que el cardenal Belluga hacía lo propio con los terrenos pantanosos e insalubres de lo que se llamaron las Pías Fundaciones (Dolores, San Felipe Neri y San Fulgencio) (Gil y Canales, 2007). Desde ese momento, la misión secular de la Comunidad de Regantes de Carrizales se ha centrado en el mantenimiento y conservación óptima de sus infraestructuras, formadas fundamentalmente por una red hídrica de más de 200 kilómetros en la que destacan los azarbes, acueductos y canales al aire libre, sin cementar ni entubar, al contrario de lo que sucede en otros lugares próximos.

El área ocupada por el Parque Natural Agrario «Los Carrizales» se localiza en la antigua albufera o golfo de Elche (Sinus Illicitanus), inexistente en la actualidad, donde confluyen los ríos Vinalopó, que atraviesa el Campo de Elche, y el Segura, que cruza la comarca del Bajo Segura y desemboca en Guardamar, creando una de las zonas pantanosas más exten-

11 Otros municipios del entorno del parque natural agrario «Los Carrizales» son Santa Pola (33.372 habitantes), Crevillente (28.362 habitantes), San Fulgencio (12.354 habitantes), Catral (9.092 habitantes) y Dolores (7.398 habitantes), que junto con Elche suman un total de 320.932 habitantes en 2011. 
sas de España, pues ambos cursos fluviales no tenían desembocaduras definidas y tanto las aguas como los sedimentos se depositaban en este lago litoral. Como ya se ha mencionado más arriba, las labores de desecación y bonificación ejecutadas por el cardenal Belluga y el duque de Arcos transformaron esta zona insalubre en tierras aptas para la actividad agrícola. Las desecaciones fueron posibles gracias al denodado esfuerzo de agricultores y nuevos colonos y a la creación de una vasta red de riego y evacuación, de herencia musulmana, por medio de la que se utilizan y reutilizan las aguas, dando lugar a una de las infraestructuras de irrigación y aprovechamiento hídrico más complejas del mundo y en la que la misma agua sirve para regar hasta tres o cuatro veces los campos. Las principales motivaciones para acometer semejante transformación radican en la necesidad de tierras de cultivo y en el ánimo de erradicar las enfermedades que suelen ir asociadas a las áreas pantanosas, como es el caso del paludismo (Canales y Segrelles, 2010). No obstante, conviene no olvidar que este sistema de irrigación tiene su origen en el siglo XIII, época en la que ya se tuvo en cuenta la importancia de los caudales hídricos para lograr que estas tierras fueran productivas, si bien es en el siglo XVIII, con las acciones del cardenal Belluga y el duque de Arcos, cuando este lugar comienza a transformarse como espacio agrario.

Las tierras pertenecientes a los agricultores, ganaderos y propietarios de charcas del Parque Natural Agrario «Los Carrizales» se ubican en la comarca alicantina del Baix Vinalopó, con un $80 \%$ de las mismas en el término municipal de Elche y el resto en el de Santa Pola. Esta zona constituye un corredor agroecológico que vertebra y une los espacios protegidos de El Hondo y de las Salinas de Santa Pola, áreas húmedas que remedan la pasada existencia de la antigua albufera. El parque agrario limita al este con el mar Mediterráneo; al norte con el Campo de Elche; al noroeste con la pedanía de San Felipe Neri, adscrita a Crevillente, municipio del Baix Vinalopo; al sureste con la sierra del Molar y el municipio de San Fulgencio, perteneciente a la comarca del Bajo Segura; y al oeste y suroeste con los términos municipales de Catral y Dolores, respectivamente, ambos del Bajo Segura (Véase al respecto la Fig. 1).

El actual sistema de riego de esta zona, aun localizándose en el término municipal de Elche, forma parte de la red de irrigación de la huerta del río Segura y se encuentra mediatizado por el clima semiárido predominante, el relieve típico de llano aluvial y el elevado nivel freático del acuífero. Ante estas condiciones, la secular preocupación de los habitantes de estas tierras siempre ha sido la reutilización del agua al máximo, de forma que el sistema de riego necesita de la existencia de dos subsistemas paralelos: el de irrigación y el de evacuación de las aguas. Todo se inicia en los azudes o presas de derivación que cortan transversalmente el lecho del río. De ahí parten las redes de acequias que distribuyen el riego por gravedad y que después se ramifican en una densa y jerarquizada malla de diverso tamaño (acequias, arrobas y regaderas) para llevar el agua a las diferentes parcelas de cultivo. Esta amplia red de suministro tiene su réplica en otra de características inversas cuyo objetivo es devolver al río el agua utilizada en la irrigación de los campos tras ser filtrada, aunque en el caso de «Los Carrizales» el agua evacuada por la malla de azarbes no va al río Segura, sino a la gola del Vinalopó en Santa Pola. Dicha trama de evacuación también se encuentra interconectada y, de menor a mayor tamaño, está compuesta por escorredores, azarbetas y azarbes. La organización y estructura de las aguas muertas o de evacuación es inversa a la que posee la trama de aguas vivas o de riego, puesto que el proceso no es de reparto, sino de 
Figura 1

PLANO DE SITUACIÓN DEL PARQUE NATURAL AGRARIO «LOS CARRIZALES». AÑO 2009

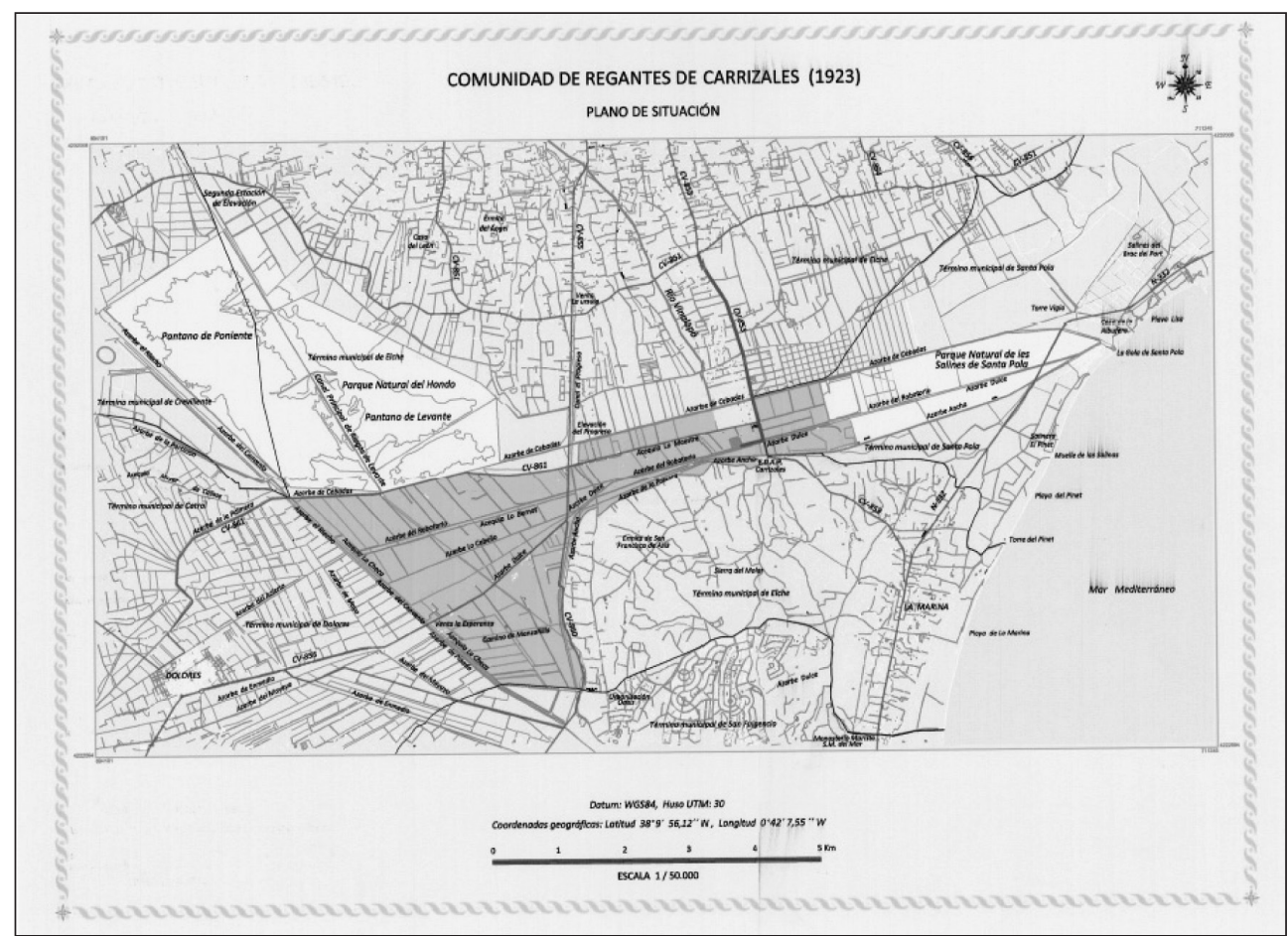

Fuente: Sebastián Polo. Elaborado para la Comunidad de Regantes de Carrizales.

integración. Es así como desde tiempos inmemoriales los agricultores de la zona consiguieron la utilización óptima y bien organizada de los escasos caudales fluviales disponibles, al mismo tiempo que se lograba una completa reutilización de las aguas del Segura para irrigar los campos varias veces. La peculiaridad de este sistema de doble circulación de las aguas deriva de la existencia de un manto impermeable a escasa profundidad. De no darse esta circunstancia se produciría el encharcamiento continuo del suelo, que se agrava además por la débil pendiente de la planicie y la dificultad de avenamiento de la misma, hecho que se debe a la presencia de un cordón de dunas en el litoral (Canales, 2004).

\section{Los diferentes usos del suelo en «Los Carrizales». El papel de la agricultura}

La primera subdivisión en cuanto a los diferentes usos del suelo que existen en el Parque Natural Agrario «Los Carrizales» se centra en la distinción entre la superficie de cultivo y la superficie no cultivada. La primera de ellas, con 781,1 hectáreas, representa el 60,0 \% de la extensión total del área (1.301,28 hectáreas), según los datos de la propia Comunidad de Regantes de Carrizales, mientras que la segunda supone el 40,0 \% y cuenta con 520,2 hectáreas (Fig. 2). 
Por lo que respecta a la superficie no cultivada (Fig. 3), la mayor extensión (289,2 hectáreas y $55,6 \%$ del total no cultivado) está ocupada por las salinas, que se localizan en el sector de la zona más próximo al parque natural de las Salinas de Santa Pola y que son de propiedad privada de la empresa Salinas de Bonmatí, S. A.

A continuación figura el espacio que se denomina naturalizado $(74,8$ hectáreas y $14,4 \%$ del total no cultivado), es decir, aquellas tierras de cultivo que han sido abandonadas por falta de rentabilidad e reintegradas al ecosistema natural, ya que el cese del riego hace que el cloruro sódico del subsuelo ascienda por capilaridad y la tierra termine por convertirse en una especie de estepa salina durante un periodo de unos 25 años.

DISTRIBUCIÓN DE LOS USOS DEL SUELO EN EL PARQUE NATURALAGRARIO «LOS CARRIZALES». AÑO 2012

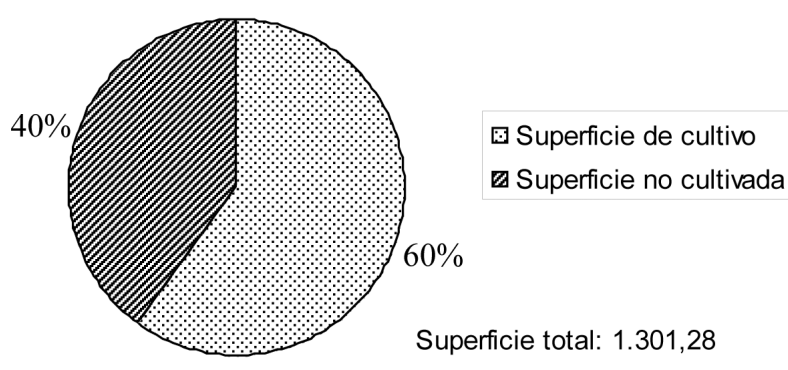

Fuente: Comunidad de Regantes de Carrizales.

Figura 3

DISTRIBUCIÓN DE LOS DIFERENTES USOS DEL SUELO EN EL PARQUE NATURAL AGRARIO «LOS CARRIZALES» RESPECTO A LA SUPERFICIE TOTAL. AÑO 2012

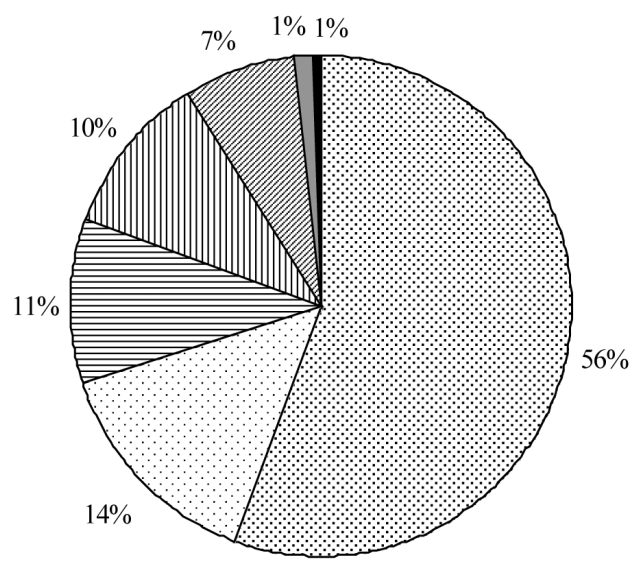

\section{․ S Salinas \\ $\square$ Naturalizadas \\ 曰Caminos y vías de comunicación 凹 Balsas y pantanos}

Azarbes, acueductos y canales $\square$ Piscifactoria

- Chalets ilegales

Superficie total no cultuvada: $520,2 \mathrm{Ha}$

Fuente: Comunidad de Regantes de Carrizales. 
Después se encuentran los caminos rurales, gestionados por el Ayuntamiento de Elche, y las vías de comunicación de dominio público, bajo la administración de la Diputación de Alicante y de la Generalidad Valenciana, que suman 55 hectáreas y representan el 10,6\% de toda la superficie no cultivada.

Asimismo, el sistema de regadío tiene una presencia muy notable en el área, pues las balsas y pantanos aglutinan 54,4 hectáreas (10,4\%) y los azarbes, acueductos y canales concentran 37,4 hectáreas (7,2\%), usos del suelo que sumados superan incluso al espacio naturalizado, pues no en vano las 91,8 hectáreas que ocupan las infraestructuras para el riego suponen el 17,6 \% del terreno no dedicado a la agricultura. Los azarbes, con 12,0 hectáreas, están gestionados por la Comunidad de Regantes de Carrizales y los acueductos, con 24,9 hectáreas, por la Confederación Hidrográfica del Segura. Por su parte, los canales pertenecen a las entidades Canal de Riegos de Levante y Canal de Riegos El Progreso, mientras que las balsas son propiedad de la Asociación de Amigos de los Humedales y se utilizan con fines ecobiológicos o bien se emplean para el control del riego, como sucede con las que gestiona la firma Nuevos Riegos El Progreso, S. A. También existen varios pantanos cuya propiedad recae en un particular y que se emplean para promover la actividad pesquera y cinegética y la oferta de paseos en barca, o por el contrario en una empresa (Peycaza, S. L.) cuyo cometido principal es también la explotación de la caza y la pesca del lugar. Los pantanos ocupan una superficie total de 50,5 hectáreas, lo que indica la importancia que han adquirido estas actividades lúdicas en el área.

En este parque natural agrario también se localiza una piscifactoría gestionada por el empresa Acuicultura Santa Pola, S. A. con una superficie de 6,4 hectáreas, cifra que representa el 1,2\% del terreno no cultivado.

Por último, y según la información proporcionada por la Comunidad de Regantes de Carrizales, existen varios chalets ilegales que ocupan una superficie total de casi tres hectáreas. Aunque en términos relativos sólo supongan el 0,6\% de las tierras no agrícolas, no se debe menospreciar la importancia de una cultura económica basada en la especulación urbanística que ha arrasado grandes espacios litorales de la zona e incluso áreas de huerta del interior en las que los agricultores han cedido el paso a los promotores, constructores e inmobiliarias y a los políticos conniventes con sus intereses (Canales y Segrelles, 2010).

La agricultura es la actividad principal en las tierras de los comuneros de Carrizales y alrededor de la que se estructura el ecosistema de la zona y su preservación, ya que no sólo no resulta destructiva para el paisaje y el territorio, sino que su presencia y desarrollo ayuda a que el entorno mantenga sus características naturales, al mismo tiempo que sirve de freno a la expansión de otras actividades más agresivas (construcción, industria, infraestructuras viarias y comerciales, vertidos) y que tanto han medrado durante los últimos lustros en otros sectores próximos, como sucede en la comarca vecina del Bajo Segura. Además, los aprovechamientos agropecuarios constituyen una actividad económica capital que en buena lógica debe permitir que los agricultores y ganaderos vivan de la tierra con dignidad y de manera sostenible y responsable, sin que el campo quede desnaturalizado por el retroceso de la agricultura y el avance del turismo o la simple consagración del medio a una utilización lúdica de los valores ambientales y naturales que se reservan para el ocio de los habitantes urbanos.

La superficie de cultivo, que representa el 60,0\% del área total (Fig. 2), se encuentra ocupada por diversas especies herbáceas y leñosas, tal como se observa en la Fig. 4, donde 
se plasma de forma proporcional el número de veces que los distintos cultivos aparecen mencionados en la relación que obra en la Comunidad de Regantes de Carrizales, toda vez que la información referente a los cultivos está distribuida por polígonos y parcelas, sin que sea posible conocer la extensión exacta dedicada a cada aprovechamiento. Como en numerosas ocasiones las parcelas se utilizan con cultivos sucesivos en una misma campaña (uno después de otro tras su cosecha) o bien con cultivos simultáneos (se desarrollan a la vez compartiendo la misma parcela), lo que refleja la Fig. 4, como se ha indicado arriba, es el número de veces que cada cultivo es mencionado. En cualquier caso, y en orden decreciente, los aprovechamientos más destacados son el trigo, las palmeras, el barbecho, las plantas forrajeras, la alcachofa, el granado, el binomio brócoli/habas, el olivo y la avena. Con porcentajes menores se encuentran el melón, la cebada, la alfalfa, el romanesco, los frutales y las patatas.

Aunque su presencia en estos campos no sea demasiado abundante en términos relativos, los productos más destacados son el melón y la granada, pues al tener un origen marino y sedimentario, la tierra de la zona experimenta una concentración de sales que motiva una concentración de azúcares en las frutas, de manera que retienen mejor el agua y evitan su deshidratación. Esto hace que los productos puedan conservarse en fresco durante mucho más tiempo y tengan una textura y un sabor únicos. Los nutrientes del suelo contribuyen al natural desarrollo de los cultivos. Asimismo, los cereales, los forrajes y la alfalfa proporcionan alimento a las más de 5.000 cabezas de ganado ovino y caprino que se crían en el área y que producen leche de elevada calidad con la que se elaboran quesos y otros productos lácteos.

Pese a la admirable labor que realizan los agricultores organizados en torno a la Comunidad de Regantes de Carrizales orientada al mantenimiento de la agricultura como elemento fundamental de la conservación de la biodiversidad y el ecosistema, no puede dejar de ser preocupante para el futuro a corto y medio plazo la edad avanzada de muchos de ellos, de

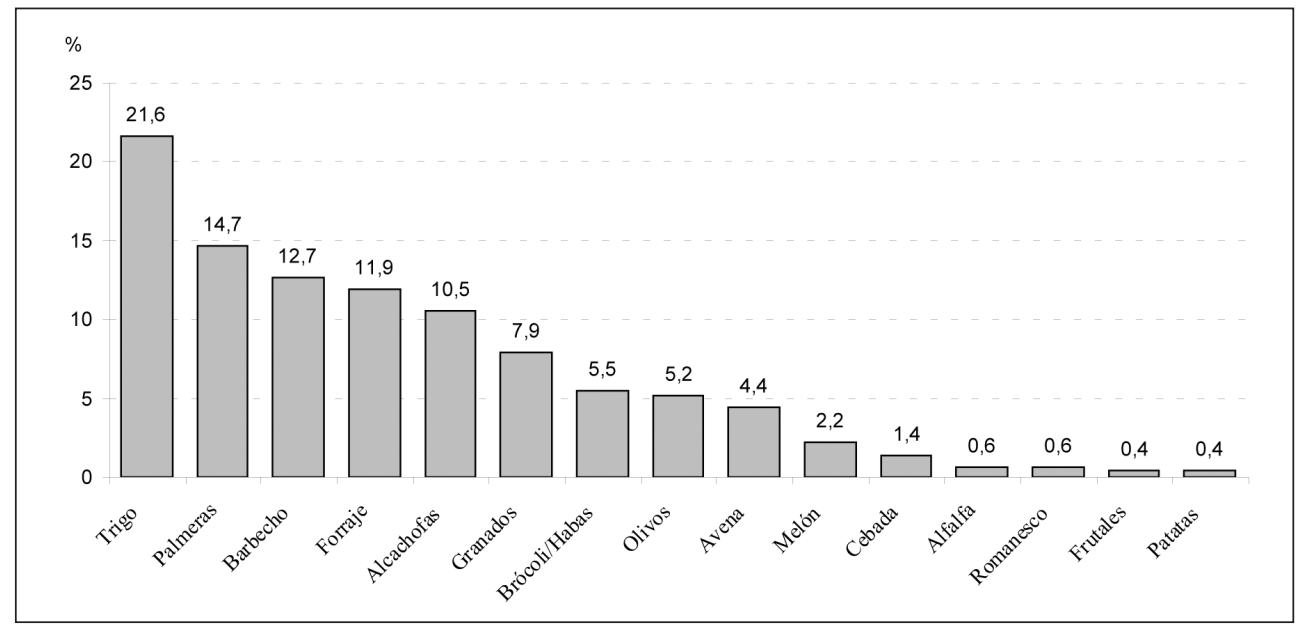

Fuente: Comunidad de Regantes de Carrizales. 
forma que queda en entredicho el necesario relevo generacional. En la Fig. 5 se observa que el $28,3 \%$ de los propietarios tiene una edad comprendida entre 55 y 64 años, mientras que el 25,2 \% cuenta con 65 y más años, es decir, ya están dentro de la edad de jubilación. El $19,5 \%$ tiene entre 45 y 54 años y sólo el 12,6 \% está por debajo de los 44 años. No obstante, uno de los principales objetivos de este parque natural agrario radica en la puesta en marcha de diferentes programas de formación que supongan la incorporación efectiva de jóvenes emprendedores al frente de los negocios agrícolas.

Entre las diversas estrategias que siguen los agricultores de la zona destaca la iniciativa que intenta fomentar la transformación de los productos in situ para no perder la revalorización que experimentan los mismos al pasar de un eslabón a otro de la cadena productiva. En este sentido, uno de los propietarios ha construido una fábrica para la obtención de zumo de granada, pues la variedad mollar, típica de Elche y áreas limítrofes, se caracteriza por su dulzor y el pequeño tamaño de sus semillas, particularidades que la convierten en un producto muy valorado en los mercados. Del mismo modo, otros objetivos fundamentales de estos agricultores ilicitanos radican en la búsqueda de producciones de elevada calidad que aprovechan las singulares características del suelo y en la creación de un sello o marca de calidad que sirva para identificar sus productos propios, cosa esta última que ya se ha conseguido con el melón de Carrizales, uno de los cultivos, junto con el granado, más emblemático del parque natural agrario, ya que se adapta perfectamente a la tierra y a las condiciones climáticas de la zona y proporciona un fruto que combina una textura firme y crujiente con un dulzor extraordinario. De momento ya han conseguido que el melón de Carrizales se venda en los supermercados de El Corte Inglés y se exporte (de momento, de forma modesta) a varios países europeos en los que es muy apreciado.

En definitiva, y dado que la agricultura tal y como se ha conocido hasta ahora ya resulta inviable desde los puntos de vista ambiental y económico, los agricultores de la Comunidad de Regantes de Carrizales han asumido la necesidad de una transformación categórica de las actividades agropecuarias que se oriente hacia un cambio técnico, metodológico y de perspectiva, de forma que en ellas queden englobados los propios productores, los consumidores y todos los niveles de la administración (local, regional, nacional y comunitaria). De ahí el proyecto que conduce a la creación de un parque natural agrario, es decir, un enclave donde se combinan la actividad agrorrural y el uso social del territorio con la protección de la biodiversidad y de los valores paisajísticos, culturales y naturales del entorno. Por lo tanto, algunos de sus objetivos serían los siguientes:

1. Protección, custodia, mantenimiento y mejora del paisaje y la biodiversidad del territorio que conforma los Carrizales.

2. Desarrollo de una agricultura integrada en el modelo agrario europeo, es decir, que sea rentable, respetuosa con el ambiente y que produzca alimentos de alta calidad.

3. Fomento y desarrollo de las industrias agroalimentarias de tipo artesanal (zumos, mermeladas, derivados lácteos, miel sin desnaturalizar) que impliquen la incorporación de un valor añadido a las producciones agrícolas, ganaderas y pesqueras. En este último caso destaca la explotación de la anguila y el mújol en las lagunas próximas al parque natural de Las Salinas de Santa Pola. En este mismo sentido se pretende involucrar al sector hostelero de la comarca y su área de influencia socioeconómica para que consuman productos del parque natural agrario. 


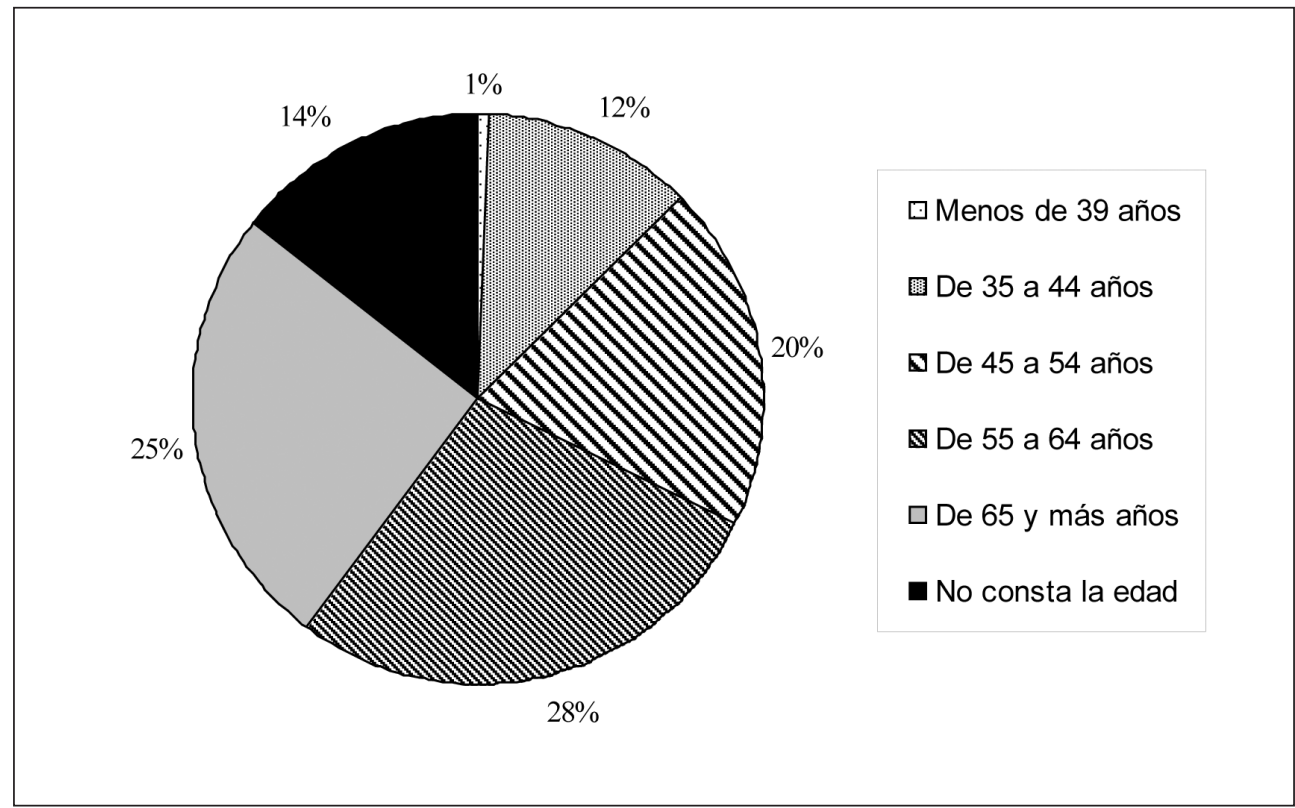

Fuente: Comunidad de Regantes de Carrizales.

4. Creación de una marca de calidad que identifique los productos y servicios del parque y que represente un valor añadido a los mismos para aportar sostenibilidad al proyecto.

5. Impulso y apoyo a la mujer rural y a las personas desempleadas, pues pueden encontrar una oportunidad de empleo en las actividades desarrolladas en este ámbito. Del mismo modo, se intenta favorecer el retorno de aquellas personas que en su momento abandonaron la agricultura en busca de mejores oportunidades laborales.

Asimismo, entre las propuestas que la Comunidad de Regantes de Carrizales ha realizado para su desarrollo en el seno del parque natural agrario, destacan el fomento de los cultivos hortofrutícolas tradicionales (granado, melón, habas, brócoli) y la recuperación de plantas autóctonas que han desaparecido del entorno, como sucede en el caso de la barrilla, el salicor o el aguazul, que en los siglos pasados fue fundamental para la producción del denominado jabón de Marsella. Esta recuperación iría asociada a la pretensión de crear una línea de cosmética natural basada en estas plantas. Y todo ello bajo las exigencias de una agricultura integrada libre de residuos donde los cultivos deberán ser objeto de una inteligente planificación, pues algunos de ellos, como el sorgo, la alfalfa o la cebada, son necesarios desde el punto de vista ambiental porque son beneficiosos para la fauna cuyo hábitat se encuentra en estas tierras. 
Para alcanzar los objetivos propuestos resulta imprescindible llevar a cabo una eficiente modernización de los regadíos que derive en una mejora de la rentabilidad del campo y en una racionalización óptima de los recursos hídricos disponibles. La red de riego histórico por gravedad debe ser conservada y en perfecto estado de uso por su valor cultural, agrícola y ecológico. Los riegos intermitentes por inundación impiden la salinización del suelo y los caudales de agua dulce que se aportan a los acueductos, y que provienen del drenaje de los campos, mejoran la calidad del agua, al mismo tiempo que permiten el desarrollo de la vida acuática y de su entorno.

La modernización de los regadíos resulta una tarea primordial para conseguir que ciertos productos emblemáticos, como el melón, mantengan su excelente calidad, aumente la productividad de su cultivo y consiga introducirse en los mercados nacionales e internacionales con garantías de éxito. Dicha modernización hídrica, proceso respaldado por la propia Generalidad Valenciana, conllevaría un aumento de más de un $30 \%$ de la productividad por hectárea y sin perjuicio para la calidad del producto, ya que la peculiaridad del melón de Carrizales se debe a las características físicas de estas tierras. Los miembros de la Comunidad de Regantes estiman que pueden colocar en los mercados autóctonos y foráneos nueve millones de kilogramos en fresco y unos dos millones de kilogramos de melón envasado en varias modalidades. Toda esta producción representará una facturación directa para el agricultor de unos diez millones de euros, sin contar el valor añadido de los productos enlatados. Aparte de la marca o sello de calidad que ya posee, se aspira a iniciar en un futuro próximo los trámites necesarios para conseguir la denominación de origen protegida (DOP), la indicación geográfica protegida (IGP) o la especialidad tradicional garantizada (ETG). Sumando el resto de productos hortofrutícolas de calidad (granada, brócoli, alcachofa, habas) y otros de la industria artesanal (queso, mermeladas, miel, zumos, jabón), las previsiones estiman que se puede producir una inyección directa de capital bruto a los negocios agrícolas de unos 20 millones de euros y una cifra aproximada de unos 500 empleos directos.

Por último, en colaboración con la Universidad de Alicante, se están investigando las múltiples propiedades medicinales, aromáticas, cosméticas, condimentarías, forrajeras y de extracción de fibras y tintes de determinadas especies arbóreas de la zona. De este modo, los agricultores dispondrán de una información adecuada que les abra la posibilidad de introducir nuevos cultivos que permitan ofrecer productos innovadores y de calidad. Incluso una empresa transnacional farmacéutica ha contactado con la Comunidad de Regantes de Carrizales con el objeto de valorar la posibilidad de comercializar extractos de varias plantas del entorno, hecho que puede actuar como revulsivo de la agricultura del parque natural agrario (Diario Información, Alicante, 14 de junio de 2011).

\section{Los recursos ambientales y el turismo en el Parque Natural Agrario}

El territorio donde se localiza el Parque Natural Agrario «Los Carrizales» se encuentra catalogado como Zona Húmeda de Especial Interés. Además, forma parte del Parque Natural de Las Salinas de Santa Pola y de la Zona Perimetral de Protección del Parque Natural de El Hondo, ambos reconocidos como Zona Ramsar, ZEPA (Zona de Especial Protección para las Aves) y LIC (Lugar de Interés Comunitario). Esta área agroecológica goza de una ubicación estratégica porque conecta y vertebra los dos parques naturales protegidos mencionados 
arriba. Al mismo tiempo, el excelente estado de conservación de su malla de azarbes y canales, mantenidos en estado natural y sin cementar ni entubar, convierten este espacio en un lugar excepcional desde los puntos de vista ambiental y de la diversidad biológica. El estado natural de los azarbes se consigue por medio de la categórica eliminación de los herbicidas para el control de la vegetación palustre, ya que el empleo de la siega mecánica mejora las condiciones del medio y permite la circulación del agua porque ésta no se estanca. El valor de esta zona húmeda se relaciona con el esfuerzo secular de sus habitantes para la construcción de un sistema de regadío que garantizara la supervivencia de la población, de modo que los paisajes cultural y natural forman un binomio equilibrado y dual en el que el aprovechamiento agropecuario no tiene por qué excluir la conservación del territorio y del ambiente.

Los terrenos agrícolas, los saladares, los canales, los azarbes y las lagunas constituyen los diferentes hábitats que se encuentran en este parque natural agrario. Cada uno de ellos mantiene una elevada biodiversidad con su flora y su fauna asociadas. Los saladares incluyen especies como el limonio, la alacranera, el salado, el junco o la sosa, vegetación típica de gran interés por su especial adaptación a los suelos húmedos y salinos. En las tierras agrícolas destaca una gran variedad de vegetación ruderal, como sucede con el lisón o la camarroja. Los carrizales son muy comunes en los azarbes, canales y lagunas, donde también aparece la vegetación acuática sumergida, como el perluc. Entre la avifauna, con más de 170 especies, sobresalen la cerceta pardilla, la canastera o la grulla común. También existen peces, como el endémico fartet o la anguila; mamíferos, como la rata de agua, la liebre o el erizo; e incluso reptiles, como la lagartija colirroja o la culebra viperina.

En 2009 se inició un proyecto denominado Humedal de los Carrizales, que intenta recrear el ecosistema original por medio de la creación de una laguna de aguas permanentes con cuatro hectáreas de superficie y sobre suelos agrícolas cuyo objetivo es favorecer la presencia de especies asociadas al ecosistema primigenio, como es el caso del fartet y la cerceta pardilla. Dicho proyecto se ha completado en su primera fase, siendo visible una lámina de agua de 10.000 metros cuadrados que ya alberga a numerosas especies. En esta iniciativa también han participado la Asociación de Naturalistas del Sureste (ANSE) y los Amigos de los Humedales del Sureste de Alicante (AHSA). Este último grupo ecologista ya está integrado en la Junta Rectora de Carrizales. Además, junto con ciertas asociaciones ecologistas y conservacionistas, como la Sociedad Española de Ornitología (SEO), AHSA y Avinença, se están preparando dos ambiciosos proyectos de custodia del territorio para la nidificación de la canastera común y para la futura declaración como reserva ornitológica de los azarbes y canales del Parque Natural Agrario «Los Carrizales».

Del mismo modo, también se tiene previsto el trazado de diversos corredores verdes que atraviesen el parque y el abandono definitivo de varias parcelas agrícolas con el objeto de que sirvan de refugio a la fauna y la flora locales. De ahí que la protección, conservación y custodia del paisaje, las acciones encaminadas hacia la mejora de la biodiversidad y el fomento y divulgación de la cultura y la sensibilidad ambiental entre la población que habita en los municipios afectados por el parque natural agrario, constituyan un objetivo estratégico de sus responsables.

Los recursos ambientales, la diversidad biológica e incluso la integración de la agricultura con el ecosistema no sólo se potencian por una cuestión ética o por el convencimiento de hacer las cosas de una manera equilibrada y sostenible, sino porque todo ello (ambiente, 
biodiversidad y agricultura) es también susceptible de convertirse en unos recursos rentables y de generar valor por medio de su utilización como espacio turístico, recreativo y de ocio. Esta zona cuenta con grandes posibilidades para aprovechar todas las oportunidades que ofrece el entorno y desarrollar varias modalidades turísticas: agroturismo y turismo rural, turismo ornitológico y de naturaleza, turismo fotográfico y deportivo, senderismo, turismo cultural.

La riqueza y variedad de aves (y de la fauna y flora en general) que habita en el lugar puede resultar un factor atractivo para atraer visitantes, pues en ciertos países, como Canadá, existe una notable afición hacia la observación ornitológica. Del mismo modo, cada día tiene más adeptos el gusto por alojarse en casas de labranza y por participar en las propias tareas agrícolas, sin olvidar el creciente interés de la sociedad por todo lo relacionado con las actividades al aire libre. De ahí que el Parque Natural Agrario «Los Carrizales» haya puesto en marcha un proyecto ecoturístico que tiene como objetivo prioritario la generación de valor a partir del aprovechamiento de la red de azarbes y caminos de la zona. Dicho proyecto consiste en la utilización de las brazas de algunos azarbes para la creación de rutas iguales a las que existen en los parques naturales y que enlacen con ellas. Estas rutas pueden seguirse caminando, en bicicleta y a caballo. Por supuesto, aparte del valor agroambiental intrínseco del área, en todo este potencial no puede obviarse su enorme patrimonio hidráulico e histórico-cultural. En efecto, el sistema de irrigación por gravedad que caracteriza a este espacio agrícola enlaza con el que existe en la comarca del Bajo Segura, ya que los caudales hídricos que dan vida a los azarbes de la zona proceden de allí. Como ya se ha comentado en otros apartados de este texto, el origen de esta trama de regadío se remonta al siglo XIII, cuando los musulmanes que habitaban aquí ya se percataron de la relevancia que tenían los caudales del río Segura para conseguir que estas tierras fueran productivas, aunque la verdadera transformación del paisaje en un espacio agrario tiene lugar en el siglo XVIII, con las desecaciones y bonificaciones del cardenal Belluga y el duque de Arcos, aspectos que sin duda gozan de un gran valor cultural e histórico capaz de atraer a aquellos visitantes interesados por conocer un patrimonio que se ha conservado hasta la actualidad. Los azarbes del Robatori, el Ample, el de la Pastora o el de D'Alt se siguen utilizando del mismo modo que en otros periodos históricos. Asimismo, ejemplos de esta tradición secular son la estación de bombeo «El Progreso» y el templo de San Francisco de Asís.

Por último, para divulgar todos los valores naturales, históricos y culturales de la zona en los mercados turísticos potenciales, la Comunidad de Regantes de Carrizales pretende editar la revista Agricultura Medioambiental, que tendrá una tirada de 9.000 ejemplares, se expresará en español e inglés y se intentará dar a conocer entre los diputados del Parlamento Europeo, sin olvidar su difusión por medio de internet con versiones en varios idiomas.

En cualquier caso, los agricultores del Parque Natural Agrario «Los Carrizales» tienen bien asumido que el turismo nunca debe convertirse en un fenómeno de masas que acabe por banalizar y desvirtuar los verdaderos recursos y funciones de la zona, esto es, la agricultura integrada en el ecosistema. El agricultor es un profesional y merece por ello una remuneración adecuada, pero no puede ni debe convertirse en un empresario turístico, un guía ambiental, un experto ornitólogo o alguien que proporciona paseos ecuestres. El turismo debe complementar las rentas agrarias y nunca sustituirlas, como pasa en muchos lugares en los que el ecoturismo acaba por marginar la agricultura y desarraigar al agricultor. 


\section{CONCLUSIONES}

Durante las últimas décadas, las rentas agrarias dependen con intensidad cada vez mayor de la relación de intercambio con los demás sectores económicos, quedando la agricultura progresivamente atrapada en una tenaza de precios difícil de superar: los que debe pagar a las industrias agrarias para adquirir los insumos que necesita para producir (maquinaria, combustibles, fertilizantes, pesticidas, semillas, piensos compuestos) y los que se ve forzada a aceptar por la venta de sus productos a las empresas agroalimentarias (mataderos, industrias cárnicas, centrales lecheras, azucareras, aceiteras, transformadoras y envasadoras de diversos productos hortofrutícolas). Sin embargo, en los tiempos más recientes es la gran distribución organizada la que controla la totalidad de la cadena agroalimentaria y la que obtiene grandes beneficios a costa de los dos eslabones más débiles: los agricultores y ganaderos y los consumidores. Su posición estratégica le permite tener un control absoluto en la negociación de los precios con los productores, al mismo tiempo que la concentración de las centrales de compra, mediatizadas también por las firmas de distribución, posibilitan que puedan acordar mediante consenso sus políticas de precios para los clientes. Al mismo tiempo, la gran distribución agroalimentaria prefiere seleccionar a sus proveedores y que éstos sean escasos, muy capitalizados y capaces de ofertar sus productos en grandes cantidades, con unas normas estrictas y estandarizadas de calidad y características y a un precio lo más bajo posible, es decir, lo que más le interesa es establecer relaciones con la agroindustria. La agricultura familiar no puede adaptarse a las duras exigencias y ve imposibilitado su acceso a los consumidores, aunque produzca de forma sostenible y respete los ecosistemas y la biodiversidad del entorno.

Con estas premisas es fácil deducir las dificultades a las que deben hacer frente los agricultores familiares, cuyas tierras se localizan en el Parque Natural Agrario «Los Carrizales», para poder vender su producción y vivir de su trabajo con dignidad. Esta agricultura integrada en el ambiente, generadora de empleo en el medio rural y de vida en los pueblos y que proporciona productos nutritivos y de elevada calidad, necesita también de un modelo de comercialización que no sea el de la gran distribución agroalimentaria organizada, sino el de los mercados próximos y circuitos mercantiles cortos y donde el consumidor sea una persona con rostro, criterio y capacidad de elección. De ahí todas las estrategias productivas y comerciales de la Comunidad de Regantes de Carrizales, ya que la creación de una marca o sello de calidad para sus productos, la revalorización de las características paisajísticas, ambientales y culturales del lugar y la apuesta clara por la transformación de sus producciones para que el valor añadido no se desvíe del control de los agricultores caminan en esta dirección.

Los comuneros de Carrizales son plenamente conscientes de que privar al mundo rural de las actividades agropecuarias es desnaturalizarlo. La agricultura es la vertebradora principal de las actividades socioeconómicas de las comunidades rurales, la garantía de la conservación del medio, la base de nuestra cultura y un patrimonio común con el que se identifican los pueblos. No obstante, tampoco olvidan que en la actualidad ya no es posible hablar de desarrollo agrícola sin considerar la necesaria diversificación económica y funcional de las áreas rurales. Esta idea constituye el origen de sus iniciativas a favor de la potenciación de la multifuncionalidad rural, es decir, el aprovechamiento de todas y cada una de las posibilidades que ofrece el entorno. Es importante, por lo tanto, conseguir nuevas fuentes de ingresos que complementen pero que no sustituyan a las rentas agropecuarias. No se trata, 
como interesada o equivocadamente se sostiene en ocasiones, de fomentar el turismo como un monocultivo rural, sino de lograr unas condiciones de vida y trabajo dignas y atractivas para los agricultores, potenciando con inversiones e imaginación una actividad agropecuaria viable y al mismo tiempo sostenible, lo que ayudará a preservar tanto el ambiente como las funciones esenciales de los espacios rurales. Es más, muchas de sus posibilidades procederán del respeto ecológico y de la preservación de la naturaleza.

Los agricultores del Parque Natural Agrario «Los Carrizales» asocian en sus planteamientos y en su actividad, como indicaba D. Chardon (2000), los conceptos de agricultor profesional y de multifuncionalidad y aglutinan las tres funciones básicas que a su juicio deben ejercer los campesinos: la función de producción agrícola, la función territorial de ocupación del espacio y conservación del ambiente y la función social de mantener el empleo en el medio rural. Sólo así se podrá hablar de viabilidad de la agricultura y, por consiguiente, de desarrollo rural y conservación ambiental.

La protección ecológica y la integridad de los ecosistemas no tienen por qué excluir necesariamente un aprovechamiento agropecuario eficiente, rentable y generador de un valor añadido elevado, contradiciendo a la vez esa ideología conservacionista y de ecología profunda que aboga por el mantenimiento de los espacios naturales libres de la presencia humana y de sus actividades productivas. La utilización agrícola y ganadera del medio se convierte en este caso en un factor territorial, ambiental y cultural de primer orden, ya que la agricultura se erige como una actividad económica necesaria para conservar la biodiversidad y el ecosistema de la zona y en la manifestación que crea un paisaje cultural de gran valor histórico que representa una seña de identidad de los pueblos.

\section{BIBLIOGRAFÍA}

CANALES MARTÍNEZ, G. (2004): «Avenamiento y utilización de aguas muertas» en La cultura del agua en la cuenca del Segura (Gil Olcina, A., coord.). Murcia. Fundación Cajamurcia, 439-477.

CANALES MARTÍNEZ, G. y SEGRELLES SERRANO, J.A. (2010): «Situación actual y perspectivas de futuro de un paisaje cultural: la huerta del Bajo Segura (Alicante)». XV Coloquio de Geografía Rural. Territorio, paisaje y patrimonio rural. Cáceres. Universidad de Extremadura y Asociación de Geógrafos Españoles.

CHARDON, D. (2000): L'agriculture au tournant du siècle. Inventer notre avenir. Strasbourg. Congrés Federal FNSEA.

DEVALL, B. y SESSIONS, G. (1985): Deep Ecology: Living as if Nature Mattered. Salt Lake City. Gibbs Smith.

DIEGUES, A. C. (2005): El mito moderno de la naturaleza intocada. São Paulo. Núcleo de Apoio à Pesquisa sobre Populações Humanas e Áreas Úmidas Brasileiras (NUPAUB). Universidade de São Paulo.

DILITIO, C. (2006): «¿Quién y qué es Douglas Tompkins?». Ecoportal.net. El directorio ecológico y natural, 28 de agosto. Disponible en http://www.ecoportal.net.

DOWIE, M. (2007): «Los refugiados del conservacionismo. Cuando la conservación implica desterrar a la gente». Ecoportal.net. El directorio ecológico y natural, 18 de enero. Disponible en http://www.ecoportal.net. 
FREIRE TRIGO, S. (2010): «El Parque Agrario de Sabadell. Contención del crecimiento urbano mediante la recuperación de un espacio agrícola para la ciudadanía» en Biblioteca $C F+S$. Ciudades para un Futuro Sostenible. Vitoria-Gasteiz y Madrid. Centro de Estudios Ambientales del Ayuntamiento de Vitoria-Gasteiz y Grupo de Investigación en Arquitectura, Urbanismo y Sostenibilidad de la Universidad Politécnica de Madrid, 22 p. Disponible en http://habitat.aq.upm.es/eacc/asabadell.html.

GEORGE, S. (2001): Informe Lugano. Barcelona. Icaria.

GIL OLCINA, A. y CANALES MARTÍNEZ, G. (2007): Residuos de propiedad señorial en España. Perduración y ocaso en el Bajo Segura. Alicante. Publicaciones de la Universidad de Alicante.

MONTASELL i DORDA, J. (2008): «El parque agrario del Baix Llobregat: una excusa para reflexionar sobre la necesidad de preservar, desarrollar y gestionar los espacios agrarios». IX Congreso Nacional del Medio Ambiente (CONAMA 9). Madrid. Diciembre. Disponible en http://www.conama9.org/conama9/download/files/MRs/65489478_ppt_JMontasell.pdf.

NACIONES UNIDAS (1987): Nuestro futuro común. Nueva York. Comisión Mundial sobre Medio Ambiente y Desarrollo.

SEGRELLES SERRANO, J.A. (2007): «La multifuncionalidad rural: realidad conflictiva en la Unión Europea, mito en América Latina». Ería, nº 72, 89-99.

SESSIONS G. (1981): «Shallow and Deep Ecology: A Review of the Philosophical Literature» en Ecological Consciousness: Essays from the Earthday X Colloquium (Hughes, J. D. y Schultz, R., ed). Washington DC, University Press of America, 391-462.

TERRICABRAS MARANGES, R. (2005): El parque agrario del Baix Llobregat (Barcelona). Una agricultura de futuro en un territorio periurbano de calidad. Girona. Fundació Agroterritori. Disponible en http://www.agroterritori.org/ficha.php?doc=361\&cid=1.

VERDAGUER VIANA-CÁRDENAS, C. (2010): «Conservación de la biodiversidad y de los usos agrícolas frente a la presión de las infraestructuras metropolitanas en el entorno de El Prat de Llobregat. Un proceso de negociación entre las administraciones local y regional y de coordinación de la planificación territorial impulsado por la presión ciudadana» en Biblioteca $C F+S$. Ciudades para un Futuro Sostenible. Vitoria-Gasteiz y Madrid. Centro de Estudios Ambientales del Ayuntamiento de Vitoria-Gasteiz y Grupo de Investigación en Arquitectura, Urbanismo y Sostenibilidad de la Universidad Politécnica de Madrid, 8 p. Disponible en http://habitat.aq.upm.es/eacc/aelprat.html. 